\title{
Right ventricular systolic function in Nigerians with heart failure secondary to hypertensive heart disease
}

\author{
Adewoye Ifeoluwa $\mathrm{A}^{2}$, Adewole Adesoji Adebiyi ${ }^{1,2}$, Adeoye Abiodun $\mathrm{M}^{1,2}$, Aje Akinyemi ${ }^{2}$
}

1. Department of Medicine, College of Medicine, University of Ibadan, Ibadan, Nigeria.

2. Department of Medicine, University College Hospital, Ibadan, Nigeria.

\begin{abstract}
Background: Right ventricular (RV) dysfunction has been shown to be a major contributor to the adverse outcomes in subjects with heart failure. Few studies evaluating the right ventricle in heart failure subjectshave been carried out in Sub-Saharan Africa. This studywas therefore designed to evaluate the right ventricular systolic function in subjects with heart failure secondary to hypertensive heart disease presenting to the University College Hospital, Ibadan Nigeria.

Methodology: Seventy-six subjects with heart failure secondary to hypertension and 92 normal controls underwent clinical, electrocardiographic and echocardiographic evaluation. Indices of right ventricular systolic function that were measured include tricuspid annular plane systolic excursion (TAPSE), tissue Doppler derived tricuspid peak systolic lateral annulus velocity $\left(\mathrm{S}^{\prime}\right)$ and right ventricular fractional areachange(RVFAC).

Results: Sixty-two (81.6\%) heart failure subjects had right ventricular systolic dysfunction, 31(40.8\%) had abnormal TAPSE, $42(55.5 \%)$ had abnormal S' while 49(64.5\%) had abnormal RVFAC. Elevated pulmonary artery systolic pressure was found in $25(32.9 \%)$ of the subjects. There was no relationship between the indices of right ventricular systolic function and the estimated systolic pulmonary artery pressures. The independent predictor of right ventricular systolic dysfunction was the right atrial size. Conclusion: Right ventricular systolic function is impaired in patients with heart failure secondary to hypertensive heart disease. There is no relationship between the indices of right ventricular systolic function and systolic pulmonary artery pressure. Further studies are needed to assess right ventricular systolic function in Nigerians.
\end{abstract}

Keywords: Hypertension, Heart Failure, Right ventricular dysfunction, Nigeria, Sub- Saharan Africa.

DOI: https://dx.doi.org/10.4314/ahs.v19i2.37

Cite as: Ifeoluwa $A A$, Adebiyi $A A$, Adeoye $A M$, Akinyemi $A$. Right ventricular systolic function in subjects with beart failure secondary to bypertensive heart disease. Afri Health Sci.2019;19(2): 2130-2139. https:/ / dx.doi.org/10.4314/abs.v19i2.37

\section{Introduction}

Heart failure (HF) is a major and growing public health problem around the world with a prevalence of more than 23 million worldwide. ${ }^{1}$ Despite the advances in the prevention and management of cardiovascular diseases, mortality in heart failure is still high. Therefore, the identification of the predictors of mortality in heart failure has been an area of extensive research. A number of studies have provided evidence that right ventricular systolicfunction is an independent prognostic factor in moderate to severe heart failure. ${ }^{2-4}$

\section{Corresponding author: \\ Adewole Adesoji Adebiyi, \\ Department of Medicine, \\ College of Medicine, \\ University of Ibadan \\ University College Hospital \\ Ibadan, Nigeria \\ Email:wadebiyi@gmail.com}

Pulmonary hypertension is considered an important contributor toexercise intolerance in heart failure. ${ }^{5,6}$ and several studies have reported an inverse relationship between right ventricular systolic function and pulmonary hypertension. ${ }^{7}$

Although there are newer and more advanced methods of assessing right ventricular systolic function, echocardiography has been reported to be equally clinically useful ${ }^{8,}$ ${ }^{9}$ and still remains an attractive tool because of its obvious advantages of non-invasiveness, low cost and easy reproducibility.

Amongst the various indices of RV systolic function that can beevaluated using echocardiography, more studies havedemonstrated the clinical utility and value of TAPSE, 2D RV FAC, and S' of the tricuspid annulus. ${ }^{10-13}$ RV FAC has been shown to correlate with RVEF by magnetic resonance imaging (MRI). ${ }^{11,14}$ TAPSE has been shown to correlate strongly with radionuclide angiographic assessment of right ventricular function. ${ }^{10} \mathrm{~S}$ ' has also been found to strongly correlate with right ventricular ejection fraction obtained by radionuclide angiography. ${ }^{15}$
(C) 2019 Adewoye et al. Licensee African Health Sciences. This is an Open Access article distributed under the terms of the Creative commons Attribution License (https://creativecommons.org/licenses/BY/4.0), which permits unrestricted use, distribution, and reproduction in any medium, provided the original work is properly cited.

African Health Sciences Vol 19 Issue 2, June, 2019 
Most of the studies on right ventricular systolic function in heart failure were carried out in Caucasians with very few studies on indigenous Africans. Heart failure in Africa is mostly attributed to non-ischaemic factors such as hypertension, valve disorders, idiopathic cardiomyopathy in contrast to western countries where ischaemic heart disease is a major contributor to the aetiology of heart failure. ${ }^{16}$ Studies across sub-Saharan Africa have documented hypertension as the commonest aetiology of heart failure in Africans. ${ }^{17}$ Local studies done in Nigeria have also reported hypertension as the commonest aetiology of heart failure in Nigerians. ${ }^{18-20}$

This study therefore aimed to evaluate the right ventricular systolic function in subjects with heart failure secondary to hypertensive heart disease and to determine the relation- ship between right ventricular systolic function and estimated systolic pulmonary artery pressure.

\section{Methodology}

This study was carried out at the University College Hospital, Ibadan, Nigeria. The study protocol was approved by the ethics committee of the hospital and each participant signed an informed consent form in accordance with the Declaration of Helsinki. The study was cross-sectional in design. The study was powered at $90 \%$ to detect a mean difference of $2.5 \mathrm{~mm}$ in the tricuspid annular plane systolic excursion between subjects with heart failure and normal controls.

Seventy-six patients with heart failure secondary to hypertensive heartdisease and ninety- two apparently healthy controls were recruited consecutively. The exclusion criteria among subjects with heart failure included those with heart failure due to aetiology other than hypertensioneven if co-existing with hypertension, co-morbidities such as ischaemic heart disease/myocardial infarction, diabetes mellitus, thyroid disease, chronickidney disease, anaemia, asthma and chronic obstructive pulmonary disease (COPD). Other exclusion criteria among subjects and controls included pregnancy, current smokers, significant alcohol use of more than 14 units perweek for women and 21 units per week for men, gout, poor echocardiographic window and refusal to give consent.

\section{Echo-cardiographic Studies}

Trans-thoracic echocardiography was performed using a Toshiba Xario ${ }^{\mathrm{TM}}$ cardiac ultrasound system on all subjects and controls in the left lateral decubitus position and mea- surements were taken according to the recommendations of the American Society of Echocardiography. ${ }^{21}$ Measures of right ventricular systolic function evaluated included tricuspid annular plane systolic excursion (TAPSE) which was acquired by placing an M-mode cursor through the tricuspid annulus, in the apical four-chamber view, and measuring the amount of longitudinal excursion of the annulus at peak systole; tissue Doppler derived tricuspid peak systolic lateral annulus velocity ( $\mathrm{S}^{\prime}$ ) was obtained from apical 4-chamber window with thepulsed Doppler sample volume placed on the lateral tricuspid annulus. Systolic pulmonary artery pressure (SPAP) was estimated by measuring the maximum velocity of the tricuspid regurgitant jet. In the absence of a gradient across the pulmonary valve, SPAP is equal to the right ventricular systolic pressure (RVSP). RVSP was derived from the tricuspid valve regurgitant jet velocity, using the simplified Bernoulli equation and combining this value with an estimate of the right atrial(RA) pressure: RVSP $=4(\mathrm{~V}) 2$ $+\mathrm{RA}$ pressure. Where $\mathrm{V}$ is the peak velocity (in meters per second) of the tricuspid valve regurgitant jet,and RA pressure was estimated from IVC diameter and respiratory changes. Inferior Vena Cava (IVC) diameter less than or equal to $2.1 \mathrm{~cm}$ that collapses greater than $50 \%$ with a sniff suggests a normal RA pressure of $3 \mathrm{~mm} \mathrm{Hg}$ (range,0-5 $\mathrm{mm} \mathrm{Hg}$ ), whereas an IVC diameter greater than $2.1 \mathrm{~cm}$ that collapses lessthan $50 \%$ with a sniff suggests a high RA pressure of $15 \mathrm{~mm} \mathrm{Hg}$ (range, 10-20 $\mathrm{mmHg}$ ). Normal resting values for SPAP values are usually defined as a peak TR gradient of 2.8 to $2.9 \mathrm{~m} / \mathrm{s}$ or a peak systolic pressure of 35 or $36 \mathrm{~mm} \mathrm{Hg}$, assuming an RA pressure of 3 to $5 \mathrm{~mm} \mathrm{Hg}{ }^{22}$

\section{Data management and analysis}

Data was analysed using $\mathrm{R}$ statistical software version 3.3.2. ${ }^{23}$ For quantitative data, the mean \pm standard deviation or the median \pm median absolute deviation - for non-normally distributed data were reported for descriptive purposes while frequencies(percentages) were reported for qualitative data. The Shappiro-Wilk's test was used to test for normality. Student's 't' test, or the Mann Whitney's test (non-parametric testing for non-normaldata) were used to test for the differences in the continuous variables between the two groups while chi-squared analysis was used to test for the differences in the categoric variables betweenthe groups. Pearson's correlation was used to evaluate the bivariate relationship between the 
parameters of RV systolic function and some clinical and echocardiographic indices. A stepwise logistic regression model was used to determine the independent correlates of RV systolic dysfunction. A two-tailed p-value of $<$ 0.05 was considered significant.

\section{Results}

A total of 168 subjects (76 patients with heart failure and

Table 1: Baseline characteristics of the subjects

\begin{tabular}{|c|c|c|c|}
\hline Variable & $\begin{array}{l}\text { Subjects } \\
n=76\end{array}$ & $\begin{array}{l}\text { Control } \\
\mathrm{n}=92\end{array}$ & P-value $t$ \\
\hline Age (years) & $55.0 \pm 13.00$ & $49.0 \pm 11.6$ & 0.0017 \\
\hline Body Mass Index (kg.m-2)‡ & $24.9 \pm 4.768$ & $25.3 \pm 4.44$ & 0.2327 \\
\hline Pulse (/min) & $88.2 \pm 12.97$ & $70.5 \pm 10.1$ & $0.0000^{*}$ \\
\hline Systolic Blood Pressure $(\mathrm{mmHg}) \ddagger$ & $116.0 \pm 20.76$ & $120.0 \pm 14.8$ & 0.5063 \\
\hline Diastolic Blood Pressure $(\mathrm{mmHg}) \ddagger$ & $79.0 \pm 13.34$ & $80.0 \pm 6.67$ & 0.3146 \\
\hline Pulse Pressure $(\mathrm{mmHg}) \ddagger$ & $40.0 \pm 14.83$ & $40.0 \pm 10.4$ & 0.0528 \\
\hline Mean Arterial Pressure (mmHg) & $90.0 \pm 14.83$ & $91.0 \pm 8.40$ & 0.7424 \\
\hline
\end{tabular}

\section{Relationship between RV function indices and number of abnormal RV function indices}
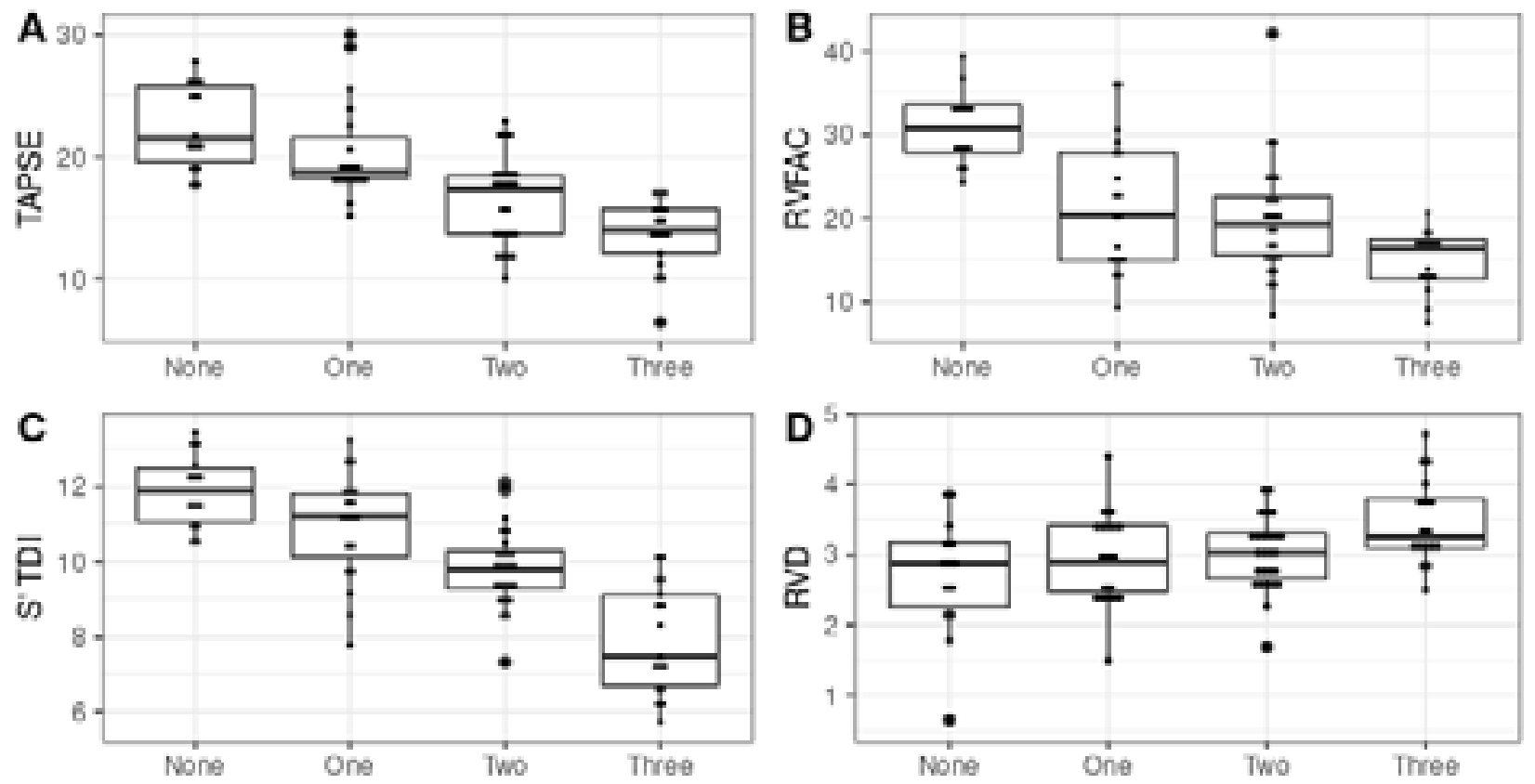

TAPSE Tricuspid annular plane systolic excursion, S' TDI Lateral Tricuspid Annular Systolic Velocity, RVFAC Right Ventricular Fractional Area Change, RVD Right Ventricular Internal Diameter

Figure 1: Relationship between RV function parameters and number of abnormal RV function indices 
Table 2: Echocardiographic parameters in the subjects

\begin{tabular}{|c|c|c|c|}
\hline Variablet & $\begin{array}{c}\text { Subjects } \\
(n=76)\end{array}$ & $\begin{array}{c}\text { Controls } \\
(n=92)\end{array}$ & P-value \\
\hline Left Atrial Diameter $(\mathrm{cm})$ & $4.65 \pm 0.667$ & $3.21 \pm 0.44$ & $0.0000^{*}$ \\
\hline Inter-ventricular Septal thickness - Diastole $(\mathrm{cm})$ & $0.93 \pm 0.208$ & $0.85 \pm 0.15$ & $0.0011^{*}$ \\
\hline LV Posterior wall thickness - Diastole $(\mathrm{cm})$ & $0.94 \pm 0.200$ & $0.85 \pm 0.15$ & $0.0000 *$ \\
\hline LV Internal Diameter - Diastole (cm) & $6.44 \pm 0.875$ & $4.60 \pm 0.59$ & $0.0000 *$ \\
\hline LV Internal Diameter - Systole $(\mathrm{cm}) \ddagger$ & $5.44 \pm 0.963$ & $2.87 \pm 0.53$ & $0.0000^{*}$ \\
\hline LV Fractional Shortening (\%) & $15.2 \pm 6.598$ & $35.9 \pm 6.40$ & $0.0000^{*}$ \\
\hline LV Ejection Fraction (\%) & $31.1 \pm 11.62$ & $65.8 \pm 8.90$ & $0.0000 *$ \\
\hline Right Atrial Diameter - major axis $(\mathrm{cm})$ & $6.19 \pm 1.060$ & $4.70 \pm 0.49$ & $0.0000^{*}$ \\
\hline Right Atrial Diameter - minor axis $(\mathrm{cm})$ & $4.70 \pm 0.652$ & $3.71 \pm 0.43$ & $0.0000^{*}$ \\
\hline Right Ventricular Internal Diameter $(\mathrm{cm})$ & $3.08 \pm 0.645$ & $2.30 \pm 0.30$ & $0.0000 *$ \\
\hline Right Ventricular Fractional Area Change (\%) $\ddagger$ & $21.2 \pm 8.041$ & $35.2 \pm 5.58$ & $0.0000 *$ \\
\hline Tricuspid Regurgitant Velocity $\left.\left(\mathrm{mm} \cdot \mathrm{s}^{-1}\right)\right)$ & $196.3 \pm 100.10$ & $0.00 \pm 0.00$ & $0.0000^{*}$ \\
\hline Right Ventricular Systolic Pressure (mmHg) & $25.0 \pm 15.17$ & $0.00 \pm 0.00$ & $0.0000^{*}$ \\
\hline Right ventricular outflow tract velocity $\left(\mathrm{m} \cdot \mathrm{s}^{-1}\right)$ & $0.58 \pm 0.141$ & $0.67 \pm 0.15$ & $0.0026^{*}$ \\
\hline Tricuspid Annular Plane Systolic Excursion (mm)‡ & $17.9 \pm 4.72$ & $22.2 \pm 2.97$ & $0.0000 *$ \\
\hline $\begin{array}{l}\text { Lateral Tricuspid Annular Systolic Velocity }\left(\mathrm{mm} \cdot \mathrm{s}^{-1}\right) \ddagger \\
\text { No of abnormal RV function parameters }\end{array}$ & $10.1 \pm 1.82$ & $13.1 \pm 1.93$ & $0.0000^{*}$ \\
\hline None & $14(18.4)$ & $84(91.3)$ & \multirow{4}{*}{$0.0000 *+\dagger$} \\
\hline One & $19(25.0)$ & $7(7.6)$ & \\
\hline Two & $26(34.2)$ & $1(1.1)$ & \\
\hline Three & $17(22.4)$ & $0(0.0)$ & \\
\hline
\end{tabular}

The limits of normal values for the indices of right ventricular systolic function were generated from the 2.5 percentile of the values obtained in the normal controls. The values generated were: TAPSE - $17.1 \mathrm{~mm}, \mathrm{~S}^{\prime}-10.3 \mathrm{~cm} / \mathrm{s}$, RV FAC - 23.6\%. Subjects were deemed to have right ventricular (RV) systolic dysfunction if they had values inany of the RV systolic function parameters below the generated cut-offpoints. The prevalence of right ventricular (RV) systolic dysfunction among the subjects with heart failure was $81.6 \%$. TAPSE was abnormal in $31(40.8 \%)$ of the subjects, $\mathrm{S}^{\prime}$ was abnormal in $42(55.8 \%)$ of the subjects while RVFAC was abnormal in $49(64.5 \%)$ of the subjects. Furthermore, 19(25.0\%), 26(34.2\%), and $17(22.4 \%)$ of the subjects had one, two and three RV systolic function parameters abnormal respectively. Figure 1 shows the relationship between RV function parameters and the number of abnormal RV function indices among the subjects.

The estimated right ventricular systolic pressure (RVSP) and hencethe systolic pulmonary artery pressure (SPAP) ranged from $10.2 \mathrm{mmHg}$ to $84.7 \mathrm{mmHg}$. The mean value was $29(14.6) \mathrm{mmHg}$. Using a cut-off value of $35 \mathrm{mmHg}$, $25(32.9 \%)$ of the patients had pulmonary hypertension. Table 3 compares clinical and echocardiographic indices in the subject with hypertensive heart failure and pulmonary hypertension and those without pulmonary hypertension. The major difference between the two groups was theincreased right atrial dimensions in the hypertensive heart failure subjects with pulmonary hypertension when compared with those without pulmonary hypertension. 
Table 3: Clinical/Echocardiographic Parameters and Pulmonary Hypertension in the Subjects

\begin{tabular}{|c|c|c|c|}
\hline Variable & $\begin{array}{l}\text { Pulmonary } \\
\text { Hypertension } \\
(n=25)\end{array}$ & $\begin{array}{l}\text { No Pulmonary } \\
\text { Hypertension } \\
(n=51)\end{array}$ & P-value ${ }^{\dagger}$ \\
\hline Age (years) $\ddagger$ & $55.0 \pm 14.83$ & $60.0 \pm 11.86$ & 0.6621 \\
\hline Body Mass Index (kg.m-2)‡ & $24.2 \pm 3.89$ & $25.0 \pm 5.21$ & 0.6072 \\
\hline Pulse (/min) $\ddagger$ & $91.0 \pm 7.41$ & $90.0 \pm 14.83$ & 0.6818 \\
\hline Systolic Blood Pressure (mmHg) & $122.6 \pm 23.59$ & $116.7 \pm 20.44$ & 0.2639 \\
\hline Diastolic Blood Pressure $(\mathrm{mmHg}) \ddagger$ & $80.0 \pm 14.83$ & $74.0 \pm 8.90$ & 0.1368 \\
\hline Mean Arterial Pressure (mmHg) & $96.6 \pm 17.73$ & $90.1 \pm 13.89$ & 0.0879 \\
\hline Left Atrial Diameter (cm) & $4.73 \pm 0.595$ & $4.64 \pm 0.782$ & 0.6325 \\
\hline Inter-ventricular Septal thickness - Diastole $(\mathrm{cm})$ & $1.00 \pm 0.223$ & $0.93 \pm 0.203$ & 0.1518 \\
\hline LV Posterior wall thickness - Diastole $(\mathrm{cm}) \ddagger$ & $1.00 \pm 0.237$ & $0.94 \pm 0.193$ & 0.1805 \\
\hline LV Internal Diameter - Diastole $(\mathrm{cm}) \ddagger$ & $6.35 \pm 0.815$ & $6.60 \pm 0.934$ & 0.6305 \\
\hline LV Internal Diameter - Systole (cm) & $5.38 \pm 0.900$ & $5.47 \pm 1.000$ & 0.7106 \\
\hline LV Fractional Shortening (\%)‡ & $15.0 \pm 7.41$ & $15.3 \pm 5.97$ & 0.5615 \\
\hline LV Ejection Fraction (\%)‡ & $31.0 \pm 13.74$ & $31.3 \pm 10.97$ & 0.7152 \\
\hline Right Atrial Diameter - major axis $(\mathrm{cm})$ & $6.66 \pm 1.020$ & $5.94 \pm 1.102$ & $0.0074 *$ \\
\hline Right Atrial Diameter - minor axis $(\mathrm{cm}) \ddagger$ & $4.97 \pm 0.400$ & $4.53 \pm 0.697$ & $0.0072 *$ \\
\hline Right Ventricular Internal Diameter (cm) & $3.18 \pm 0.533$ & $2.96 \pm 0.742$ & 0.1907 \\
\hline Right Ventricular Fractional Area Change (\%)‡ & $20.6 \pm 8.45$ & $18.5 \pm 7.77$ & 0.4292 \\
\hline Tricuspid Regurgitant Velocity (mm.s-1)) & $294.5 \pm 48.28$ & $144.0 \pm 66.41$ & $0.0000 *$ \\
\hline Right Ventricular Systolic Pressure $(\mathrm{mmHg}) \ddagger$ & $44.4 \pm 9.04$ & $19.4 \pm 7.56$ & $0.0000 *$ \\
\hline Right ventricular outflow tract velocity (m.s-1)‡ & $0.58 \pm 0.163$ & $0.59 \pm 0.148$ & 0.9207 \\
\hline Tricuspid Annular Plane Systolic Excursion (mm) & $17.9 \pm 6.39$ & $17.9 \pm 3.73$ & 0.9847 \\
\hline Lateral Tricuspid Annular Systolic Velocity (mm.s-1) & $10.4 \pm 1.52$ & $9.90 \pm 1.947$ & 0.2741 \\
\hline
\end{tabular}

Table 4 shows the correlation of the parameters of RV systolic function withsome clinical and echocardiographic variables. TAPSE correlated with the LV ejection fraction and negatively correlated with right atrial diameter and
RV internal diameter while $S^{\prime}$ had negative correlations with right atrial diameter and RV internal diameter. RVFAC had positive correlation with LV ejection fraction and negative correlation with LV internal diameter. 
Table 4: Correlation of RV systolic function parameters with Clinical and Echocardiographic Parameters

\begin{tabular}{lccccccc}
\hline \multicolumn{1}{c}{ Variable } & \multicolumn{2}{c}{ TAPSE } & \multicolumn{2}{c}{ S' $^{\prime}$} & \multicolumn{2}{c}{ RVFAC } \\
& $\mathrm{r}$ & $\mathrm{p}$-value & $\mathrm{r}$ & $\mathrm{p}$-value & $\mathrm{r}$ & $\mathrm{p}$-value \\
\hline Body Mass Index & 0.202 & 0.0808 & 0.036 & 0.7565 & 0.213 & 0.0644 \\
Left Atrial Diameter & -0.162 & 0.1612 & -0.081 & 0.4861 & -0.086 & 0.4584 \\
LV Ejection Fraction & 0.293 & $0.0102^{*}$ & 0.158 & 0.1720 & 0.341 & $0.0026^{*}$ \\
LV Internal Diameter - Diastole & -0.109 & 0.3493 & -0.151 & 0.1933 & -0.218 & 0.0583 \\
LV Internal Diameter - Systole & -0.196 & 0.0903 & -0.110 & 0.3438 & -0.321 & $0.0047^{*}$ \\
LV Mass Index & 0.127 & 0.2755 & 0.190 & 0.1000 & 0.014 & 0.9048 \\
Right Atrial Diameter - major axis & -0.338 & $0.0028^{*}$ & -0.297 & $0.0093^{*}$ & -0.100 & 0.3901 \\
Right Ventricular Internal Diameter & -0.316 & $0.0054^{*}$ & -0.329 & $0.0037^{*}$ & -0.169 & 0.1446 \\
Right Ventricular Systolic Pressure & -0.034 & 0.7690 & 0.074 & 0.5252 & -0.053 & 0.6494 \\
Tricuspid Annular Plane Systolic Excursion & & & 0.485 & $0.0000^{*}$ & 0.354 & $0.0017^{*}$ \\
Lateral Tricuspid Annular Systolic Velocity & & & & & 0.328 & $0.0039^{*}$ \\
\hline LV: Left Ventricle, *statistical significance & & & & & &
\end{tabular}

A stepwise logistic model was evaluated to determine the independent correlates of RV systolic dysfunction among subjects with heart failure. The explanatory variables included in the model were the age and gender of the subjects, body mass index, DBP, left atrial diameter, left ventricular internal diameter, LV ejection fraction, $\mathrm{RV}$ internal diameter, right atrial major-axis diameter and RV outflow tract velocity. The only determinant of RV systolic function in this study is the right atrial dimension. (Table 5).

Table 5: Independent Relations of RV Systolic Dysfunction in the Subjects

\begin{tabular}{lccc}
\hline & Odds Ratio & p-value & $95 \%$ Conf. Intervals \\
\hline Right Ventricular Outflow Tract Velocity & 0.13 & 0.3942 & $0.001-0.698$ \\
Right Atrial Diameter - major axis & 3.11 & 0.0060 & $1.477-7.663$ \\
Left ventricular ejection fraction & 0.94 & 0.0715 & $0.867-1.003$ \\
\hline
\end{tabular}

$p$-value $=0.0045$, Nalgelkerke $R^{2}=0.486,{ }^{*}$ statistical significance 


\section{Discussion}

In this study, about $80 \%$ of our subjects with heart failure secondary to hypertensive heart disease have impaired RV systolic function. Also, about one-third of subjects with hypertensive heart disease in this study had elevated pulmonary artery pressure which however, had no significant association with RV systolic dysfunction in the study population. The LV ejection fraction, right atrial and RV dimensions are associated with parameters of RV systolic function while right atrial dimension is the only independent correlate of RV systolic dysfunction in this group of subjects with hypertensive heart failure.

The finding of high prevalence of RV systolic dysfunction in heartfailure seen in this study supports finding from other studies that had documented varying prevalence of RV systolic dysfunction in subjects with heart failure. Puwanant and his colleagues ${ }^{24}$ studied right ventricular systolic function in subjects with heart failure using RV FAC, S' and TAPSE. However, the study group was heterogenous with respect to the aetiology of heart failure: $51 \%$ had coronary artery disease, $37 \%$ had diabetes and $32.5 \%$ had cardiomyopathies. The subjects were grouped into heart failure with preserved ejection fraction (HFPEF) and heart failure with reduced ejection fraction (HFREF). They reported a finding of a prevalence of $40 \%, 50 \%, 33 \%$ for TAPSE, S' and RV FAC respectively in those with HFPEF and 76\%,73\%, 63\% in those with HFREF. In comparison with this study in which $89.5 \%$ of the subjects with heart failure had HFREF, the study of Puwanant et al. ${ }^{24}$ had a much higher prevalence of abnormal TAPSE and S' for the subjects with HFREF. The prevalence of abnormal RVFAC was comparable inboth studies. The marked difference in the prevalence of abnormal TAPSE and S' may be accounted for by the difference in the aetiology of heart failure between the subjects in the two studies. Coronary artery disease causes regional wall abnormalities which may affect indices of right ventricular systolic function like TAPSE and $\mathrm{S}^{13}$ to a greater extent than RV FAC. Hypertension is likely to affect RV FAC more than TAPSE and S' because of ventricular interdependence. ${ }^{25}$ In actual fact, the prevalence of abnormal RVFAC was slightly higher in this study than in the study of Puwanant et al. ${ }^{24}$

Ojji and his colleagues ${ }^{4}$ in a prospective study of 611 subjects with hypertensive heart failure found RV systolic dysfunction - by TAPSE - in $44.5 \%$ of his subjects. This is comparable with the prevalence of abnormal TAPSE of $40.8 \%$ obtained in our study despite a higher cut-off point $-17.1 \mathrm{~mm}$ versus $15 \mathrm{~mm}$ - used in our study.

Abnormal RV systolic function has been shown to be a major adverse factor in the prognosis of heart failure ${ }^{26-28}$. Thus, there is a need for increased emphasis on the evaluation of the right heart in heart failure and more efforts at investigation of therapies directed at the right heart.

Our study found no relationship between the indices of right ventricular systolic function and estimated pulmonary artery systolic pressure. There is conflicting data on the pulmonary vasculature haemodynamics in hypertension. Fiorentini and his colleagues had observed that pulmonary vascular resistance rises in parallel with peripheral vascular resistance due to the "concept that the vasomotility of the greater and lesser circulation in hypertension is disturbed by the same type of disorder". ${ }^{29}$ On the other hand, Fagard et al. ${ }^{30}$ reported that that there is neither a primary nor a secondary effect of systemic hypertension on the pulmonary vasculature in patients with World Health Organization stages I to II essential hypertension. Kjaergaard et al. ${ }^{31}$ in their study on right ventricular function in heart failure using TAPSE also reported that there was no association between systolic pulmonary artery pressure and TAPSE. Karaye and colleagues $^{32}$ in their study on hypertensive subjects - without heart failure also observed that pulmonary artery systolic pressure (PASP) was a correlate of TAPSE while S' had no relationship with PASP. Ghio and colleagues ${ }^{33}$, in their prognostic study of right ventricular systolic function and pulmonary artery pressure(PAP) in patients with chronic heart failure, found an inverse relationship between pulmonary artery pressure (PAP) and RV ejection fraction in heart failure. However, they also observed subjects with preserved RV function despite elevated PAP and other subjects with abnormal RV function and normal PAP They reported that their data demonstrated that RV function may be preserved despite elevated PAP and that RV dysfunction may be observed even in patients with normal PAP. They also noted that the inverse relationship between PAP and RV dysfunction was seen in the patients with RV dysfunction resulting from RV after-load mismatch such as in dilated and ischaemic cardiomyopathy.

Since the mechanism of right ventricular dysfunction inhypertension results more from ventricular interdependence thanchanges in the pulmonary vasculature, ${ }^{30}$ this 
may explain why in this study, there was a failure to observe the inverse relationship between PASP and the indices of right ventricular systolic function, which has been documented in heart failure.

Another explanation for the failure of this study to demonstrate any relationship between PASP and RV systolic function is that over diuresis has been documented to reduce pulmonary artery systolic pressure ${ }^{8}$; some of the recruited patients had chronic heart failure and had been on long term diuretic therapy.

In univariate analyses, the relations of TAPSE found in our study were LV ejection fraction, right atrial diameter and RV internal diameter. This is similar to findings from other studies ${ }^{4,31}$ in which TAPSE was found to be signicantly related to the LV ejection fraction. The effect of LV ejection fraction on right ventricular function had been attributed to the effects of ventricular interdependence. ${ }^{25,34}$ In our study, only the right atrial dimension was the independent correlate of RV systolic function our subjects. Ojji and colleagues ${ }^{4}$ had noted the significant associations of right atrial size and LV ejection fraction as independent correlates of TAPSE in their study. However in our study, LV ejection fraction had no independent relationship with RV systolic dysfunction. This could be due to our use of composite values of TAPSE, S' and RVFAC as our measure of RV systolic dysfunction while Ojjiand colleagues only used TAPSE to define RV systolic dysfunction. The contribution of right atrial function to heart failure wasinvestigated by Ojahi Haghighi and colleagues $^{35}$. They suggested that diminished right atrial function might play critical role in the pathophysiological process of heart failure patients. Further studies on the role of the right atrium in the heart failure process areneeded.

Several studies had attempted to validate echocardiographic parameters of RV function using cardiac magnetic resonance imaging(CMRI) as gold standard.11,36,37 These echocardiographic parameters correlated significantly with CMRI derived RV ejection fraction. The sensitivity and specificities of the parameters were TAPSE $(83.4 \%, 70.0 \%), S^{\prime}(100 \%$,

$66 \%)$ and RV FAC (40\%,80\%). The authors suggested that TAPSE and S' provided better accuracy than RV FAC in subjects with pulmonary hypertension. ${ }^{37}$
Our study generated the cut-off points for the parameters of right ventricular function from the values of the control subjects. These values are comparable to the limits of RV function parameters guidelines of the American Society of Echocardiography ${ }^{13}$ apart from the RVFAC. Our cut-off limits compared with the ASE guidelines are TAPSE - $17.1 \mathrm{~mm}$ versus $16 \mathrm{~mm}, \mathrm{~S}^{\prime} 10.3 \mathrm{~cm} / \mathrm{s}$ versus 10 $\mathrm{cm} / \mathrm{s}$ and RVFAC $23.6 \%$ versus $35 \%$. The ASE limits were generated mostly from normal Caucasians. However, few normative studies have been carried out among African subjects. The marked difference in the cut-off points for RVFAC indicate that studies to define the limits of normal RV function parameters in indigenous Africans are needed.

Although our study subjects were heart failure patients secondary to hypertension with the exclusion of other causes of heart failure, the contribution of subclinical coronary artery disease to the heart failure could have been missed as coronary artery disease was excluded largely on clinical and electrocardiographic grounds alone without myocardial perfusion imaging and/or coronary angiography.

\section{Conclusion}

Right ventricular systolic dysfunction is present in about $80 \%$ of Nigerians with heart failure secondary to hypertensive heart disease. It is therefore important that the assessment of RV function should form partof the echocardiographic assessment of subjects with heart failure. Though pulmonary arterial hypertension is found in about a third of our subjects, it had no relationship with the degree of right ventricular dysfunction. The contribution of right atrial function to the pathophysiology and prognosis ofheart failure is an area that needs further clarification.

\section{References}

1. Roger VL. Epidemiology of Heart Failure. Circulation Research. 2013;113:646-659.

2. De Groote P, MillaireA, Foucher-Hossein C, Nugue O,Marchandise X, Ducloux G, et al. Right Ventricular Ejection Fraction Is an Independent Predictor of Survival in Patients with Moderate Heart Failure. Journal of the American Collegeof Cardiology. 1998;32:948-954.

3. Field ME, Solomon SD, Lewis EF, Kramer DB, Baugh- 
man KL, Stevenson LW, et al. Right Ventricular Dysfunction and Adverse Outcome in Patients with Advanced Heart Failure. Journal of Cardiac Failure. 2006;12:616-620. 4. Ojji DB, Lecour S, Atherton JJ, Blauwet LA, Alfa J, and Sliwa K. Right Ventricular Systolic Dysfunction Is Common inHypertensive Heart Failure: A Prospective Study in Sub-Saharan Africa. Plos One. 2016;11:e0153479. 5. Abramson SV, Burke JF, Kelly JJ, Kitchen JG, Dougherty MJ, Yih DF, et al. Pulmonary Hypertension Predicts Mortality and Morbidity in Patients with Dilated Cardiomyopathy. Ann. Intern. Med. 1992;116:888-895.

6. Hunt SA. Pulmonary Hypertension in Severe CongestiveHeart Failure: How Important Is It? J. Heart Lung Transplant.1997;16:S13-15.

7. Yang T, Liang Y, Zhang Y, Gu Q, Chen G, Ni XH, et al. Echocardiographic Parameters in Patients with Pulmonary Arterial Hypertension: Correlations with Right Ventricular Ejection Fraction Derived from Cardiac Magnetic Resonance and Hemodynamics. PloS One. 2013;8:e71276. 8. Ghio S, Recusani F, Klersy C, Sebastiani R, Laudisa ML, Campana C, et al. Prognostic Usefulness of the Tricuspid Annular Plane Systolic Excursion in Patients with Congestive Heart Failure Secondary to Idiopathic or Ischemic Dilated Cardiomyopathy. Am. J. Cardiol. 2000;85:837-842. 9. Karatasakis GT, Karagounis LA, Kalyvas PA, Manginas A, Athanassopoulos GD, Aggelakas SA, et al. Prognostic Significance of Echocardiographically Estimated Right Ventricular Shortening in Advanced Heart Failure. Am. J. Cardiol. 1998;82:329-334.

10. Kaul S, Tei C, Hopkins JM, and Shah PM. Assessment of RightVentricular Function Using Two-Dimensional Echocardiography. American Heart Journal. 1984;107:526531.

11. Lai WW, Gauvreau K, Rivera ES,Saleeb S, Powell AJ, and Geva T. Accuracy of Guideline Recommendations for Two-Dimensional Quantification of the Right Ventricle byEchocardiography. The International Journal of Cardiovascular Imaging. 2008;24:691-698.

12. López-Candales A, Dohi K, Rajagopalan N, Edelman K, Gulyasy B, and Bazaz R. Defining Normal Variables of Right Ventricular Size and Function in Pulmonary Hypertension: An Echocardiographic Study. Postgraduate Medical Journal. 2008;84:40- 45.

13. Rudski LG, Lai WW, Afilalo J, Hua L, Handschumacher MD, Chandrasekaran K, et al. Guidelines for the EchocardiographicAssessment of the Right Heart in Adults: A Report from the American Society of Echo- cardiography. Journal of the American Society of Echocardiography. 2010;23:685-713.

14. Anavekar NS, Gerson D, Skali H, Kwong RY, Yucel EK, and Solomon SD. Two- Dimensional Assessment of RightVentricular Function: An Echocardiographic-MRI Correlative Study. Echocardiography (Mount Kisco, N.Y.). 2007;24:452-456.

15. Meluź1n J, Spinarová L, Bakala J, Toman J, Krejć1 J, Hude P, et al. Pulsed Doppler Tissue Imaging of the Velocity of Tricuspid Annular Systolic Motion; a New, Rapid, and Non-Invasive Method of Evaluating Right Ventricular Systolic Function. European Heart Journal. 2001;22:340-348.

16. Ntusi NBA and Mayosi BM. Epidemiology of Heart Failure in Sub-Saharan Africa. Expert Review of Cardiovascular Therapy. 2009;7:169-180.

17. Kingue S, Dzudie A, Menanga A, Akono M, Ouankou M, andMuna W. A New Look at Adult Chronic Heart Failure in Africain the Age of the Doppler Echocardiography: Experience of the Medicine Department at Yaounde General Hospital. Annales de cardiologie et d'angeiologie. 2005;54:276-283.

18. Karaye KM and Sani MU. Factors Associated with Poor Prognosis among Patients Admitted with Heart Failure in a Nigerian Tertiary Medical Centre: A Cross-Sectional Study. BMC Cardiovascular Disorders. 2008;8:16.

19. Ojji DB, Alfa J, Ajayi SO, Mamven MH, and Falase AO. Pattern of Heart Failure in Abuja, Nigeria: AnEchocardiographic Study. Cardiovascular Journal of Africa. 2009;20:349-352.

20. Onwuchekwa AC and Asekomeh GE. Pattern of Heart Failure in a Nigerian Teaching Hospital. Vascular Health and Risk Management. 2009;5:745-750.

21. Sahn DJ, DeMaria A, Kisslo J, and Weyman A.Recommendations Regarding Quan- titation in M-Mode Echocardiography: Results of a Survey of Echocardiographic Measurements. Circulation. 1978;58:1072-1083. 22. Badesch DB, Champion HC, Sanchez MAG, Hoeper MM, Loyd JE, Manes A, et al. Diagnosis and Assessment of Pulmonary Arterial Hypertension. Journal of the American College of Cardiology. 1 Suppl 2009;54:S55-S66.

23. R Core Team. R: A Language and Environment for Statistical Computing. R Foundation for Statistical Computing, 2016.

24. Puwanant S, Priester TC, Mookadam F, Bruce CJ, Redfield MM, andChandrasekaran K. Right Ventricular Function in Patients with Preserved and Reduced Ejec- 
tion Fraction Heart Failure. European Journal of Eechocardiography: The Journal of the Working Group on Echocardiography of the European Society of Cardiology. 2009;10:733- 737.

25. Jurcut R, Giusca S, La Gerche A, Vasile S, Ginghina $\mathrm{C}$, and Voigt JU. The Echocardiographic Assessment of the RightVentricle: What to Do in 2010? European Journal of Echocardiography: The Journal of the Working Group on Echocardiography of the European Society of Cardiology. 2010;11:81-96.

26. Kjaergaard J, Akkan D, Iversen KK, Køber L, Torp-Pedersen C, and Hassager C. Right Ventricular Dysfunction as an Independent Predictor of Short- and Long-Term Mortality in Patients with Heart Failure. European Journal of Heart Failure. 2007 Jun-Jul;9:610-616.

27. Darahim KE. Right Ventricular Systolic Echocardiographic Parameters in Chronic Systolic Heart Failure and Prognosis. The Egyptian Heart Journal. 2014;66:317-325.

28. Guazzi M, Bandera F, Pelissero G, Castelvecchio S, Menicanti L, Ghio S, et al. Tricuspid Annular Plane Systolic Excursion and Pulmonary Arterial Systolic Pressure Relationship in Heart Failure: An Index of Right Ventricular Contractile Function and Prognosis. American Journal of Physiology - Heart and Circulatory Physiology. 2013;305:H1373-H1381.

29. Fiorentini C, Barbier P, Galli C, Loaldi A, Tamborini $G$, Tosi E, et al. Pulmonary Vascular Overreactivity in Systemic Hypertension. A Pathophysiological Link between the Greater and the Lesser Circulation. Hypertension (Dallas, Tex. : 1979) 6 Pt 1 1985;7:995-1002.

30. Fagard R, Lijnen P, Staessen J, Verschuere J, and Amery A. The Pulmonary Circulation in Essential Systemic Hypertension. The American Journal of Jardiology. 1988;61:1061-1065.

31. Kjaergaard J, Iversen KK, Akkan D, Møller JE, Køber
LV, Torp-Pedersen C, et al. Predictors of Right Ventricular Function as Measured by Tricuspid Annular Plane Systolic Excursion in Heart Failure. Cardiovascular UltraSound. 2009; 7:51.

32. Karaye KM, Sai'du H, and Shehu MN. Right Ventricular Dysfunction in a Hypertensive Population Stratified byPatterns of Left Ventricular Geometry. Cardiovascular Journal of Africa. 2012;23:478-482.

33. Ghio S, Gavazzi A, Campana C, Inserra C, Klersy C, SebastianiR, et al. Independent and Additive Prognostic Value of RightVentricular Systolic Function and Pulmonary Artery Pressure in Patients with Chronic Heart Failure. Journal of the American College of Cardiology. 2001;37:183-188.

34. Santamore WP and Dell'Italia LJ. Ventricular Interdependence: Significant Left Ventricular Contributions to Right Ventricular Systolic Function. Progress in Cardio- vascular Diseases. 1998 Jan-Feb;40:289-308.

35. Ojaghi Haghighi Z, Naderi N, Amin A, Taghavi S, Sadeghi M, Moladoust H, et al. Quantitative Assessment of Right A trial Function by Strain and Strain Rate Imaging in Patients with Heart Failure. Acta Cardiologica. 2011;66:737-742.

36. Sato T, Tsujino I, Ohira H, Oyama-Manabe N, Yamada A, Ito YM, et al. Validation Study on the Accuracy of Echocardiographic Measurements of Right Ventricular Systolic Function in Pulmonary Hypertension. Journal of the American Society of Echocardiography: Official Publication of the American Society of Echocardiography. 2012;25:280-286.

37. Sato T, Tsujino I, Ohira H, Oyama-Manabe N, Ito YM,Takashina C, et al. Accuracy of Echocardiographic Indices for Serial Monitoring of Right Ventricular Systolic Function in Patients with Precapillary Pulmonary Hypertension. PLoS One. 2017;12. 